Diabetes

Adherence (\%) ${ }^{\mathrm{a}}$

Stimulation intensity $(\mathrm{dB})^{\mathrm{b}}$

Constant
Weather sensitivity

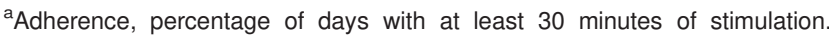
bStimulation intensity, ratio of therapeutic stimulation to sensation threshold expressed in decibels (20log[therapy/sensation]).

All coefficients $P<0.05$.

Disclosure of Interests: Xuan Kong Employee of: Xuan Kong is an employee of NeuroMetrix, Inc., Dawn Chesher Employee of: Dawn Chesher is an employee of GlaxoSmithKline Consumer Healthcare. DOI: 10.1136/annrheumdis-2019-eular.5866

\section{THU0491 RELIABILITY AND VALIDITY OF THE ISTANBUL LOW BACK PAIN DISABILITY INDEX IN LUMBAR RADICULOPATHY}

Savaş Sencan ${ }^{1}$, Didem Erdem ${ }^{2}$, Serhad Bilim¹, Mehmet Tuncay Duruöz ${ }^{2}$.

${ }^{1}$ Marmara University School of Medicine, Department of Physical Medicine and Rehabilitation, Division of Pain Medicine, Istanbul, Turkey; ${ }^{2}$ Marmara University School of Medicine, Department of Physical Medicine and Rehabilitation, Division of Rheumatology, İstanbul, Turkey

Background: The Istanbul Low Back Pain Disability Index (ILBPDI) was developed to assess the disability in patients with mechanical low back pain with 18 daily activities questions (1).

Objectives: The aim of this study is to investigate the validity and reliability of the İstanbul Low Back Pain Disability Index in lumbar radiculopathy. Methods: Patients who were diagnosed with radiculopathy due to lumbar spinal stenosis and/or disc herniation by physical examination and imag ing methods were included in the study. Data about age, sex, body mass index (BMI), disease duration (month) were noted. Short Form 36 (SF-36) was used to assess the quality of life. Disability due to low back pain was assessed with Oswestry Low Back Disability Questionnaire. The severity of low back pain and extremity pain due to radiculopathy were assessed on the Visual Analogue Scale (VAS).

The reliability of ILBPDI was determined by internal consistency (Cronbach's alpha coefficient). The construct validity (convergent and divergent validities) was evaluated. The correlations of the ILBPDI with SF-36, Oswestry Low Back Disability Questionnaire, and the VAS scores of the low back pain and radiculopathy were assessed for convergent validity. The relations of the ILBPDI with age, BMI, and disease duration were assessed for divergent validity. The construct validity of the ILBPDI scale was determined by Spearman's correlation coefficient. The descriptive analysis was done for demographic data. $\mathrm{P}<0.05$ accepted as significant. SPSS 20.0 (Statistical package for social sciences for Windows 20.0) program was used for the statistical analysis.

Results: The mean age of 82 patients (44 female, 38 male) with lumbar radiculopathy was 45.45 (SD: 11.96) years. The median (min-max) duration of disease was $5(1-120)$ months. The mean BMl of patients was 29.09 (SD: 5.04). The mean score of ILBPDI was 30.73 (SD: 17.04) ant the mean score of Oswestry Low Back Disability Questionnaire was 52.73 (SD: 16.98).

The Cronbach's alpha coefficient of the ILBPDI for internal consistency was 0.764 . The ILBPDI score had moderate and significant positive correlations with Oswestry Low Back Disability Questionnaire (rho: 0.610, $\mathrm{p}<0.005)$. Statistically significant but low correlation was detected between ILBPDI and the VAS score of radiculopathy (rho: 0.285 , p: 0.010 ), but there was no correlation with the VAS score of low back pain $(p>0.05)$. As for the correlations between the ILBPDI total score and SF-36 subgroups, significant negative correlations were detected with physical functioning (rho: $-0.672, p<0.005$ ), physical role limitation (rho: -0.230 , p: 0.038 ), bodily pain (rho: $-0.546, p<0.005$ ), general health (rho: $-0.262, p$ : 0.017 ), and social function (rho: $-0.337, p<0.005$ ) subgroups of the SF36. There were no significant correlations between ILBPDI and age, disease duration, and BMI ( $p>0.05)$

Conclusion: The Istanbul Low Back Pain Disability Index is a valid and reliable instrument in patients with lumbar radiculopathy. This is a preliminary study. The study will continue for the factor analysis.

\section{REFERENCE:}

[1] Duruoz MT et al. Development and validation of a functional disability index for chronic low back pain. J Back Musculoskelet Rehabil. 2013; 26: 45-54.
Disclosure of Interests: Savaş Sencan: None declared, Didem Erdem: None declared, Serhad Bilim: None declared, Mehmet Tuncay Duruöz Grant/research support from: Abvie, Speakers bureau: Novartis, AMGEN, Abdi İbrahim, İlko DOI: 10.1136/annrheumdis-2019-eular.6010

\section{THU0492 EFFICACY OF US-GUIDED HYALURONIC ACID INJECTIONS IN ACHILLES AND PATELLAR MID- PORTION TENDINOPATHIES: A PROSPECTIVE MULTICENTRIC CLINICAL TRIAL}

Antonio Frizziero ${ }^{1}$, Filippo Vittadini ${ }^{2}$, Francesco Oliva ${ }^{3}$, Mario Vetrano ${ }^{4}$, Maria Chiara Vulpiani ${ }^{4}$, Nicola Giordan ${ }^{5}$, Stefano Masiero ${ }^{1}$, Nicola Maffulli ${ }^{3} .{ }^{1}$ University of Padua, Padova, Italy; ${ }^{2}$ Metropolitan City of Venice, Venice, Italy; ${ }^{3}$ University of Salerno, Fisciano, Italy; ${ }^{4}$ Sapienza University of Rome, Roma, Italy, ${ }^{5}$ Fidia Farmaceutici S.p.A., Abano Terme, Italy

Background: Achilles and patellar tendinopathies are common clinical conditions that determine chronic pain and functional impairment. Conservative treatment can be effective, but it is time-consuming and it requires intensive patient compliance.

Hyaluronic acid $(\mathrm{HA})$ is a key component of the extracellular matrix, and its anti-inflammatory, lubricant and analgesic properties are well established in osteoarthritis. Growing pre-clinical evidence point toward a possible role of $\mathrm{HA}$ in the management tendon pathology, while clinical evidences are still lacking.

Objectives: The primary objective was to assess the efficacy of a new formulation of $\mathrm{HA}(20 \mathrm{mg} / 2 \mathrm{ml} ; 500-730 \mathrm{kDa})$, obtained from biofermentation, in function improvement on VISA-A and VISA-P scores at 90 days of follow-up in patients with Achilles or patellar tendinopathy.

Secondary objectives were to evaluate improvement in pain (NRS-11), US parameters (tendon composition and neovascularization), and quality of life (EQ-5D). Safety of this new HA formulation was also evaluated.

Methods: This was a prospective, open-label, multicenter clinical trial. Thirty-five patients (25in AT group; 9 patients in PT group), who satisfied strict inclusion and exclusion criteria, were recruited over a 4-month period. Each patient received 1 injection weekly for 3 weeks under USguidance at the painful site of tendinopathy, and was evaluated at 14 45 and 90 days after the procedure. Subjects were instructed to record on a diary any intake of the permitted rescue medication for pain relief (i.e. paracetamol up to $3 \mathrm{~g}$ per day) throughout the study period and to interrupt treatment at least 24 hours prior to each visit.

Results: Significant improvement on VISA-A $(23.22 \pm 23.17 ; 95 \% \mathrm{Cl}: 13.20$; $33.24 ; p<.0001)$ occurred, and improvement on VISA-P was also revealed (19.25 $\pm 11.61 ; 95 \% \mathrm{Cl}: 9.54 ; 28.96 ; \mathrm{p}=0.0022)$. NRS-11 score significantly decreased in the AT group $(4.52 \pm 3.25 ; 95 \% \mathrm{Cl}:-5.93 ;-3.12 ; \mathrm{p}<0.0001)$ and in the PT group $(-4.75 \pm 3.20 ; 95 \% \mathrm{Cl}:-7.42 ;-2.08 ; \mathrm{p}=0.0040)$.

Significant improvement of US parameters in the AT group was evidenced (McNemar's test; $p=0.0016$ and $p=0.0114$, respectively), while in the PT group the presence of these clinical symptoms showed only a tendency to decrease ( $p=0.3173$ for both). EQ-5D-5L total score tended to increase in both the AT and PT groups (mean change vs. baseline at day 90 equal to $15.96 \pm 18.95$ (range: $-50 ; 45$ ) and $15.50 \pm 32.42$ (range: 40; 71), respectively).

Conclusion: Three US-guided HA injections may improve pain and function in patients with Achilles and patellar tendinopathy for up to 90 days of follow-up. Amelioration in tendon structure, neovscolarization and clinical parameters may also be achieved. The hyaluronic acid injection was also safe and well tolerated.

\section{REFERENCES:}

[1] Frizziero A, Salamanna F, Giavaresi G, Ferrari A, Martini L, Marini M, Veicsteinas A, Maffulli N, Masiero S, Fini M. Hyaluronic acid injections protect patellar tendon from detraining-associated damage. Histol Histopathol. 2015 Sep;30(9):1079-88

[2] Lynen N, De Vroey T, Spiegel I, Van Ongeval F, Hendrickx NJ, Stassijns G. Comparison of Peritendinous Hyaluronan Injections Versus Extracorporeal Shock Wave Therapy in the Treatment of Painful Achilles' Tendinopathy: A Randomized Clinical Efficacy and Safety Study. Arch Phys Med Rehabil. 2017 Jan;98(1):64-71

Disclosure of Interests: Antonio Frizziero: None declared, Filippo Vittadini: None declared, Francesco Oliva: None declared, Mario Vetrano: None declared, Maria Chiara Vulpiani: None declared, Nicola Giordan Employee of: Fidia Farmaceutici, Stefano Masiero: None declared, Nicola Maffulli: None declared

DOI: 10.1136/annrheumdis-2019-eular.3260 